\title{
SEOM-GECP-GETTHI Clinical Guidelines for the treatment of patients with thymic epithelial tumours (2021)
}

\author{
J. Remon ${ }^{1}$ (1) R. Bernabé2 $\cdot$ P. Diz ${ }^{3} \cdot$ E. Felip $^{4} \cdot$ J. L. González-Larriba ${ }^{5} \cdot$ M. Lázaro ${ }^{6} \cdot$ X. Mielgo-Rubio $^{7}$ A. Sánchez ${ }^{8}$. \\ I. Sullivan ${ }^{9} \cdot$ B. Massutti ${ }^{10}$
}

Accepted: 20 January 2022 / Published online: 5 February 2022

(c) The Author(s) 2022

\begin{abstract}
Thymic epithelial tumours (TET) represent a heterogeneous group of rare malignancies that include thymomas and thymic carcinoma. Treatment of TET is based on the resectability of the tumour. If this is considered achievable upfront, surgical resection is the cornerstone of treatment. Platinum-based chemotherapy is the standard regimen for advanced TET. Due to the rarity of this disease, treatment decisions should be discussed in specific multidisciplinary tumour boards, and there are few prospective clinical studies with new strategies. However, several pathways involved in TET have been explored as potential targets for new therapies in previously treated patients, such as multi-tyrosine kinase inhibitors with antiangiogenic properties and immune checkpoint inhibitors (ICI). One third of patient with thymoma present an autoimmune disorders, increasing the risk of immune-related adverse events and autoimmune flares under ICIs. In these guidelines, we summarize the current evidence for the therapeutic approach in patients with TET and define levels of evidence for these decisions.
\end{abstract}

Keywords Thymic epithelial tumours $\cdot$ Chemotherapy $\cdot$ Lenvatinib $\cdot$ Nivolumab $\cdot$ Multidisciplinary

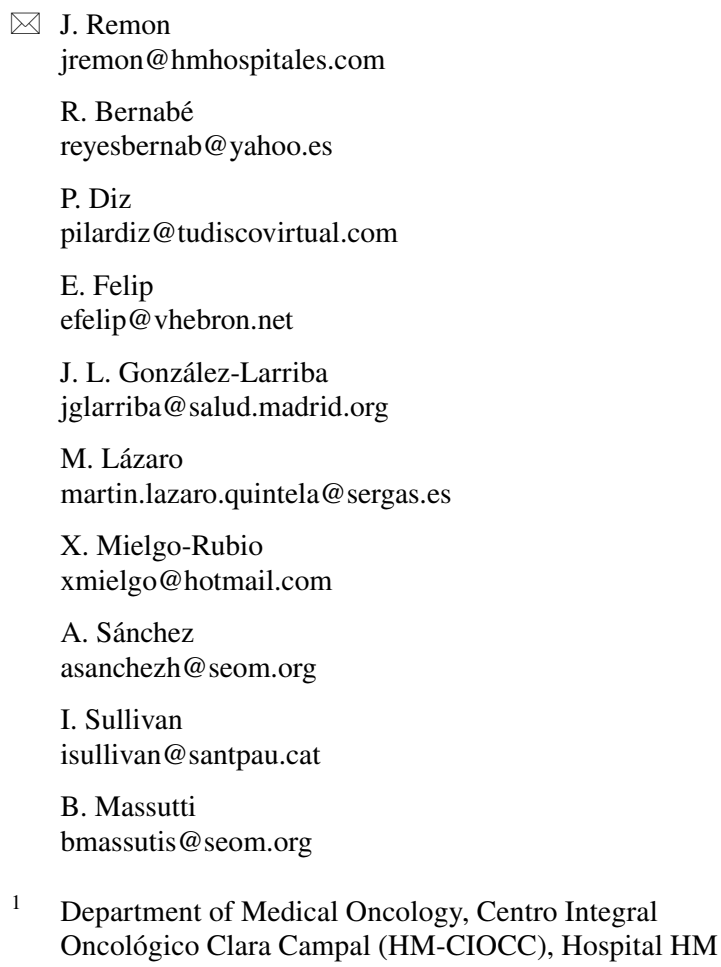

1 Department of Medical Oncology, Centro Integral Oncológico Clara Campal (HM-CIOCC), Hospital HM

Nou Delfos, HM Hospitales, Avinguda de Vallcarca, 151, 08023 Barcelona, Spain

2 Department of Medical Oncology, Hospital Universitario Virgen del Rocío, Seville, Spain

3 Department of Medical Oncology, Hospital Universitario de León, León, Spain

4 Department of Medical Oncology, Vall d'Hebron University Hospital and Vall d'Hebron Institute of Oncology (VHIO), Barcelona, Spain

5 Department of Medical Oncology, Hospital Universitario Clínico San Carlos, Madrid, Spain

6 Department of Medical Oncology, Hospital Alvaro Cunqueiro, Vigo, Spain

7 Department of Medical Oncology, Hospital Universitario Fundación Alcorcón, Madrid, Spain

8 Department of Medical Oncology, Consorcio Hospitalario Provincial de Castellón, Castellón de la Plana, Spain

9 Department of Medical Oncology, Hospital de la Santa Creu i Sant Pau, Barcelona, Spain

10 Department of Medical Oncology, Hospital General Universitario de Alicante, Alicante, Spain 


\section{Methodology}

These guidelines are based on leading studies published in peer review journals. The Infectious Diseases Society of America grading system was used to assign levels of evidence and grades of recommendation [1].

\section{Epidemiology}

Thymic epithelial tumours (TET) represent a group of rare, heterogeneous malignancies arising from thymic epithelial cells, and represent $50 \%$ of all anterior mediastinal masses. TET entities include thymomas $(\mathrm{T})$ with subtypes (A, AB, B1, B2, B3) and aggressive thymic carcinomas (TC) [2]. In the European Union, the overall annual incidence of TET is 0.18 per 100.000 (T: 0.14/100.000, and TC: 0.01/100.000) [3]. The overall incidence in Spain remains unknown, but as an example, in Madrid 18 new cases were reported in 2019 [4]. The incidence of TETs is slightly higher in men than women (1.4:1), and increases with age, reaching a peak in the seventh decade of life. However, among AfroAmericans the incidence is higher in younger people than among whites [5]. There are no identified risk factors for developing TETs. However, a higher incidence of TETs has been reported in multiple endocrine neoplasia type 1 [6]. Similarly, in patients with TET, several studies have documented rates of second malignancies ranging from 8 to $31 \%$, particularly thymomas [7]. The prognosis of TET correlates with the histological subtype, with a 5-year overall survival (OS) of $\sim 80 \%$ and $\sim 45 \%$ for T and TC, respectively [8]. Due to the rarity of this disease, there are few prospective clinical studies, and most recommendations stem from retrospective cohort studies or expert opinions. (Table 1).

\section{Pathological classification}

The thymus is composed of lymphocytes and epithelial cells, however,

only the epithelial cells can develop cancer. According to the World Health Organization pathological classification, TET entities include [2]:

- Thymoma A: epithelial cells (at least focally); paucity or absence of immature $\mathrm{T}$ cells throughout the tumour.

- Thymoma AB: spindle shaped epithelial cells (at least focally);

- abundance of immature T cells focally or throughout the tumour.
- Thymoma B1: abundance of immature T cells, areas of medullary differentiation; paucity of polygonal or dendritic epithelia cells without clustering.

- Thymoma B2: increased numbers of single or clustered polygonal or dendritic epithelial cells intermingled with abundant immature T cells.

- Thymoma B3: sheets of polygonal slightly to moderately atypical epithelial cells; absent or rare intercellular bridges; paucity or absence of intermingled immature T cells.

- Rare thymoma: thymoma micronodular, metaplastic thymoma.

- Thymic carcinoma: squamous (the most common), basaloid, adenocarcinoma, lymphoepithelioma-like carcinoma and others.

- Neuroendocrine tumours may occur in the thymus, and will not be discussed in these guidelines.

Immunohistochemistry may help in the diagnosis, as cytokeratin 20 is negative in TET, whereas PAX8 is positive, and in contrast to squamous non-small cell lung cancer up to $80 \%$ of TCs express either CD5 or CD117. The expression of CD20 occurs in $50 \%$ of A or AB thymomas, and GLUT1 expression occurs in $~ 50 \%$ of B3 thymoma and TC. Finally, in patients with undifferentiated mediastinal carcinoma, the expression of NUT or inactivation of SMARCA4 could support the diagnosis of middle NUT carcinoma or sarcoma of mediastinum, respectively.

\section{Diagnosis}

\section{Radiological diagnosis}

Standard imaging for thymic tumours is intravenous (i.v.) contrast-enhanced computed tomography (CT) scan of the thorax and abdomen, allowing a complete exploration of the mediastinum and the pleura [IV, A] as a common site of metastatic disease, particularly for thymoma. CT scan is equal or superior to magnetic resonance imaging (MRI), except in cystic lesions [9] [IV, B] and other benign lesions such as thymic hyperplasia. In these cases, MRI is recommended due to the high sensitivity of T1-weighted gradient echo images for detecting microscopic fat [10]. Similarly, MRI could be useful in assessing mediastinal invasion in locally advanced disease with potential surgical options.

18-Fluorodeoxyglucose positron emission tomography (PET)-scan has a sensitivity of $83 \%$ and a specificity of $58 \%$ [10] for thymus masses, and is not generally recommended [IV, C]. The PET scan can be considered in the cases of TET with aggressive histology, TET in advanced stages to complete the staging work-up or further characterize lesions suspicious for recurrences. 
Table 1 Recommendations for diagnosis, treatment and follow-up of patients with thymic epithelial tumours

\begin{tabular}{|c|c|}
\hline Pathology & $\begin{array}{l}\text {-Thymic epithelial tumours are classified according to the WHO histopathological classification } \\
\text {-Immunohistochemistry is useful for confirming the diagnosis of TC (CD5 /CD117 positive) [V,A] }\end{array}$ \\
\hline Radiology & $\begin{array}{l}\text {-The diagnosis of any thymic epithelial tumour relies on a differential diagnosis with other anterior mediastinal } \\
\text { tumours and non-malignant thymic lesions } \\
\text {-Standard is contrast-enhanced CT scan of the thorax [IV, A] } \\
\text {-MRI is recommended in patients with hyperplasia or cystic lesion [IV, B] } \\
\text {-PET scan is not generally recommended to assess thymic masses [IV, C] }\end{array}$ \\
\hline Baseline biopsy & $\begin{array}{l}\text {-Not required if there is high suspicion of thymic epithelial tumour and upfront surgical resection is achievable } \\
\text { [IV, E]. Biopsy is required in all other clinical situations [IV, A] }\end{array}$ \\
\hline Staging & $\begin{array}{l}\text { Post-surgical TET should be routinely staged according to the Masaoka-Koga staging system [III, A] and the 8th } \\
\text { edition of the TNM classification [V, A] }\end{array}$ \\
\hline Surgery & $\begin{array}{l}\text {-Treatment is based on the resectability of the tumour. Surgical resection is the mainstay of treatment if complete } \\
\text { resection is deemed to be achievable upfront [IV, A] } \\
\text {-Median sternotomy is the standard [IV, A] } \\
\text { - Complete thymectomy including the tumour, the residual thymus gland and perithymic fat is preferred [IV, B] } \\
\text { - Routine removal of anterior mediastinal and anterior cervical nodes is recommended [IV, A] } \\
\text {-Minimally invasive surgery is an option for presumed stage I-II tumours [IV, C] } \\
\text { - Surgery of recurrent lesions is recommended if feasible }\end{array}$ \\
\hline Radiotherapy & $\begin{array}{l}\text {-Postoperative radiotherapy is recommended in stage III, thymic carcinoma and } \geq \mathrm{R} 1 \text { resection }[\mathrm{IV}, \mathrm{B}] \\
\text {-Post-operative radiotherapy should start within } 3 \text { months of complete resection [V, B] } \\
\text {-Definitive radiotherapy is recommended as part of a sequential chemoradiotherapy strategy for patients not suit- } \\
\text { able for surgery or if complete resection is not feasible [III, A] }\end{array}$ \\
\hline Perioperative chemotherapy & $\begin{array}{l}\text {-Adjuvant chemotherapy is not indicated in thymoma [III, E] and could be considered in thymic carcinoma from } \\
\text { stage II } \\
\text {-Induction chemotherapy ( } 2-4 \text { cycles) is standard in locally advanced TET [III, A] and PAC is the most common } \\
\text { regimen [III, A]. Following that, surgery should be performed if complete resection is deemed achievable }\end{array}$ \\
\hline Metastatic disease & $\begin{array}{l}\text {-Platinum-based chemotherapy is the standard of care in patients with metastatic disease not suitable for local } \\
\text { treatment [III, A] } \\
\text {-Complete resection or radical radiotherapy of recurrent lesions is recommended when achievable } \\
\text {-There is no standard second line, but carboplatin-paclitaxel, gemcitabine-capecitabine, pemetrexed, or oral } \\
\text { etoposide are recommended } \\
\text {-Lenvatinib, sunitinib and everolimus [IIIA] are potential targeted therapies } \\
\text {-Immunotherapy is not a standard of care }\end{array}$ \\
\hline Follow-up & $\begin{array}{l}\text {-Baseline CT scan within 3-4 months of surgical resection. [V, C] } \\
\text {-For completely resected stage I-II thymoma: annual CT scan for } 5 \text { years, then every } 2 \text { years. [V, C] } \\
\text {-For stage III-IV thymoma, thymic carcinoma or after R1 or R2 resection: CT scan every } 6 \text { months for } 3 \text { to } \\
5 \text { years, thereafter annually. [V, C] } \\
\text {-Continue follow-up for } 10-15 \text { years. [V, C] }\end{array}$ \\
\hline
\end{tabular}

\section{Baseline pathological assessment}

The need for pre-treatment biopsy depends on the resectability of the tumour, and it is not required if the diagnosis of thymic tumour is highly probable and upfront surgical resection is achievable [IV, E]. In other scenarios, either surgical or percutaneous core needle biopsy, which has a sensitivity of up to $90 \%$, is required [11]. Pleural spaces should be respected to avoid tumour cell seeding. Fine-needle aspiration is generally not recommended [IV, D]. [11].

\section{Autoimmune disorders in thymic epithelial tumours}

The thymus gland plays a key role in the development of immune tolerance. Autoimmune disorders (AID) are found in up to $30 \%$ of patients with $\mathrm{T}$ and in around $3 \%$ of patients with TC $[12,13]$. In normal conditions, in the thymus those
$\mathrm{T}$ cells that react against self-antigens are destroyed. However, the AIDs are associated with inactivation of the autoimmune regulator (AIRE) gene within the thymic medulla, hampering the expression of tissue-specific self-antigens that are not recognized by the $\mathrm{T}$ cells. This results in multi-organ autoimmune disease due to self-reactive $\mathrm{T}$ cells escaping from the thymus and entering the periphery where they can cause autoimmunity [14]. Therefore, as AIDs are not paraneoplastic syndromes, they do not evolve in parallel with tumour evolution.

AID are usually associated with favourable features (i.e., earlier stage of the disease and complete resection status), but they are not an independent prognostic factor for patients with TETs [13]. The most common AID is myasthenia gravis (MG). Up to $30 \%$ of patients with $\mathrm{T}$ either present with or are eventually diagnosed with $\mathrm{MG}$, whereas, only $10 \%$ to $20 \%$ of patients with MG present 
$\mathrm{T}$ [13]. MG in TET is seropositive for the acetylcholine receptor antibody, and as these antibodies remain positive irrespective of TET evolution they do not need to be monitored. In some rare cases, TET-related MG is associated with anti-MUSK antibodies. Other AIDs have also been reported in TET, such as Good's syndrome, pure red cell aplasia, thyroiditis and lupus [12] (Table 2). Therefore, a multidisciplinary approach involving specialists in internal medicine, neurology and others is advised, especially in patients with MG scheduled for surgery.

\section{Initial evaluation}

The initial evaluation should include radiological studies, a complete history, a full clinical examination (paying particular attention to neurological signs), routine immunological tests, a complete blood cell count with reticulocytes and serum protein electrophoresis, antiacetylcholine receptor (if positive, electromyogram is not required), and anti-nuclear antibodies tests $[\mathrm{V}, \mathrm{A}]$. If other causes of the mediastinal mass are suspected, it is recommended test serum levels of $\beta$-human chorionic gonadotropin to rule out seminomas, along with elevated alpha-fetoprotein in non-seminomatous germcell tumours. Lymphoma may be considered in patients with rapid onset of B-signs, coexistent lymphadenopathy, or elevated lactate dehydrogenase.

\section{Staging of thymic epithelial tumours}

The most common classification is the Masaoka-Koga staging system [III, A], which correlates with OS. MasaokaKoga staging can only be performed after surgical resection of the tumour. This classification has been recently updated in a consensus document [15] (Table 3).

Scientific societies have recently proposed using the tumour-node-metastasis (TNM)-based staging system for TET, based on an analysis of OS using a retrospective international database of more than 10,000 cases [V, A] [16] (Table 4). The WHO classification correlates with both, the Masaoka-Koga and the 8th edition of the TNM staging classification, showing higher risk of advanced stages with B3 thymoma and TC [17].

Currently, the use of the TNM system as a guide to therapy has yet to be assessed, therefore, Masaoka-Koga staging is still the standard system in the routine management of patients, particularly for adjuvant radiotherapy, although both staging systems must be applied.

\section{Therapeutic strategies}

It is strongly recommended that the treatment of patients with TET be discussed in multidisciplinary tumour boards (MTB). This is particularly important when assessing resectability, even in locally advanced disease, as feasibility is mostly based on the surgeon's expertise [IV, B]. The MTB is even more important in rare cancers, as clinical expertise
Table 2 Selected autoimmune disorders according to functional organ systems

\begin{tabular}{ll}
\hline Neuromuscular & Endocrine \\
-Myasthenia Gravis & - Thyroiditis \\
-Peripheral neuropathy & -Autoimmune pituitary diseases \\
-Encephalomyelitis and limbic encephalitis & -Cushing's syndrome \\
-Neuromyotonia (Isaacs' syndrome) & -Addison's disease \\
-Stiff Person syndrome & -Type I diabetes \\
-Polymyositis & \\
Haematological & Dermatological \\
-Pure red cell aplasia & - Pemphigus \\
-Good's syndrome & - Lichen planus \\
-Haemolytic anaemia & - Alopecia areata \\
-Pernicious anaemia & - Vitiligo vulgaris \\
-Pancytopenia & \\
Immune system & Miscellaneous \\
-Systemic lupus erythematosus & - Glomerulopathies \\
-Rheumatoid arthritis & - Ulcerative colitis \\
-Sjogren's syndrome & -Giant cell myocarditis \\
-Dermatomyositis/myositis & \\
\hline
\end{tabular}


Table 3 Staging of thymic epithelial tumours: Masaoka-Koga-based staging system [15]

\begin{tabular}{ll}
\hline Masaoka-Koga stage & Definition \\
\hline I & -Grossly and microscopically completely encapsulated tumour including: \\
& *Invasion into but not through the capsule \\
& *In the absence of capsule, absence of invasion into surrounding tissues \\
& Microscopic transcapsular invasion $(<3 \mathrm{~mm})$ \\
IIA & -Gross extension into normal thymus or perithymic fat surrounding the tumour (microscopically confirmed) \\
IIB & -Macroscopic adherences to pleura or pericardium without invasion \\
& -Microscopic invasion of the mediastinal pleura, visceral pleura or pericardium \\
III & -Direct invasion into the lung parenchyma \\
& -Invasion into the phrenic or vague nerves \\
& -Invasion into or penetration through major vascular structures \\
& -Adherence (i.e. fibrous attachment) of lung or adjacent organs only if there is mediastinal pleural or pericar- \\
& dial invasion (microscopically confirmed) \\
IVA & Microscopically confirmed separate nodules in the visceral or parietal pleural, pericardial or epicardial surfaces \\
IVB & Lymphogenous or hematogenous metastasis \\
\hline
\end{tabular}

Table 4 Tumour-node-metastasis staging [16]

\begin{tabular}{|c|c|c|c|c|}
\hline \multirow[t]{6}{*}{$\mathrm{T}$} & $\mathrm{T} 1$ & \multicolumn{3}{|c|}{ Tumour encapsulated extending into the mediastinal fat; may involve the mediastinal pleura } \\
\hline & T1a & \multicolumn{3}{|c|}{ Tumour with no mediastinal pleural involvement } \\
\hline & $\mathrm{T} 1 \mathrm{~b}$ & \multicolumn{3}{|c|}{ Tumour with direct invasion of mediastinal pleura } \\
\hline & $\mathrm{T} 2$ & \multicolumn{3}{|c|}{ Tumour with direct invasion of pericardium } \\
\hline & $\mathrm{T} 3$ & \multicolumn{3}{|c|}{$\begin{array}{l}\text { Tumour with direct invasion of lung, brachiocephalic vein, superior vena cava, chest wall, phrenic } \\
\text { nerve, hilar (extrapericardial) pulmonary vessels }\end{array}$} \\
\hline & $\mathrm{T} 4$ & \multicolumn{3}{|c|}{ Tumour with invasion of aorta, arch vessels, intrapericardial artery, myocardium, trachea, oesophagus } \\
\hline \multirow[t]{3}{*}{$\mathrm{N}$} & No & \multicolumn{3}{|c|}{ No regional lymph nodes } \\
\hline & $\mathrm{N} 1$ & \multicolumn{3}{|c|}{ Metastasis in anterior (perithymic) nodes } \\
\hline & $\mathrm{N} 2$ & \multicolumn{3}{|c|}{ Metastasis in deep intrathoracic or cervical lymph nodes } \\
\hline \multirow[t]{3}{*}{ M } & M0 & \multicolumn{3}{|c|}{ No pleural, pericardial or distant metastases } \\
\hline & M1a & \multicolumn{3}{|c|}{ Separate pleural or pericardial nodule(s) } \\
\hline & M1b & \multicolumn{3}{|c|}{ Pulmonary intraparenchymal nodule or distant organ metastases } \\
\hline \multicolumn{2}{|l|}{ Stage } & $\mathrm{T}$ & $\mathrm{N}$ & M \\
\hline \multicolumn{2}{|l|}{ I } & $\mathrm{T} 1$ & No & M0 \\
\hline \multicolumn{2}{|l|}{ II } & $\mathrm{T} 2$ & No & M0 \\
\hline \multicolumn{2}{|l|}{ IIIA } & $\mathrm{T} 3$ & NO & M0 \\
\hline \multicolumn{2}{|l|}{ IIIB } & $\mathrm{T} 4$ & No & M0 \\
\hline \multicolumn{2}{|l|}{ IVA } & Any $\mathrm{T}$ & $\mathrm{N} 1$ & M0 \\
\hline & & Any $\mathrm{T}$ & N0,1 & M1a \\
\hline \multirow{2}{*}{\multicolumn{2}{|c|}{ IVB }} & Any $\mathrm{T}$ & $\mathrm{N} 2$ & M0, 1a \\
\hline & & Any $T$ & Any N & M1b \\
\hline
\end{tabular}

is more likely to be limited, and evidence-based decisionmaking is difficult [18-20].

\section{Surgery}

The treatment of TET is based on complete resectability of the tumour. If it is achievable, upfront surgical resection is the cornerstone of treatment in T1-T3 (IIIA) according to the 8th edition of the TNM classification [IV,A] and certain patients with stage IVA (specially thymoma) [V,B] [21]. In thymoma, 10 year OS rates after surgery clinically meaningful $-90 \%$ and $70 \%$ for stage I and II, and $55 \%$ and $35 \%$ for stage III and IVA, respectively. Patients who undergo complete resection achieve significantly better survival [22].

The standard approach is median sternotomy [IV, A]. Complete thymectomy (tumour, the residual thymus gland, and perithymic fat) is generally the preferred surgical approach to reduce risk of recurrence [23] [IV, B]. If the tumour is widely invasive (stage III and selected patients with IVa) en bloc removal of all affected structures should be 
performed [IV, A]. In this scenario, upfront induction chemotherapy should be discussed, especially in TC. Complete resection positively impacts outcomes $[24,25]$; however, OS and disease free survival (DFS) are worse in TC. The areas with uncertain resection margins should be marked with clips to allow accurate delivery of postoperative radiotherapy [21, 25] [IV, B]. Phrenic nerve preservation does not impact survival, but increases the risk of local recurrence, so the benefit should be weighed up, particularly in patients with MG [26] [IV, C]. Minimally invasive surgery carried out by fully trained thoracic surgeons is only an option in stage I and possibly certain stage II tumours $(<5 \mathrm{~cm}$ and no sign of invasion of intrathoracic vessels, lung, pericardium or trachea) [IV, B] [27].

Although the impact of lymphadenectomy on survival in TET has not been demonstrated, following the new TNM classification routine lymphadenectomy of mediastinal and anterior cervical lymph nodes is recommended [16] [IV, A]. For stage III/IV tumours, sampling of other regions (paratracheal, aortopulmonary window and subcarinal area) is advised [IV, B]. Complete dissection $(\mathrm{N} 1+\mathrm{N} 2)$ is recommended in TC, due to the high rate of lymphatic spread $(20 \%$ versus $3 \%$ in thymomas) [V, B] [28].

Finally, surgery also plays a role in the recurrences of TET [IV, A], as complete resection of recurrent lesions is associated with favourable outcomes [21].

\section{Radiotherapy}

Postoperative radiotherapy (PORT) for TET has been associated with longer OS, particularly in stage IIB to III disease and positive margins (R1) [29]. However, although a beneficial effect of PORT in terms of recurrent free survival and OS has been shown in TC [21], the role of PORT is more controversial in T, even in stage III, and there is one ongoing prospective clinical trial testing PORT in this setting (RADIO-RYTHMIC trial, NCT04731610).

Currently, PORT for $\mathrm{T}$ is indicated in stage III/IVA [IV, $\mathrm{B}$ ], as well as in $\mathrm{R} 1$ or $\mathrm{R} 2$ resection irrespective of the stage. It can be proposed in stage IIB in patients with aggressive histology, such as B2/B3 thymoma [IV, C]. Regarding TC, postoperative $\mathrm{RT}$ is optional in stage $\mathrm{I}[\mathrm{V}, \mathrm{C}]$, and should be considered in all other stages [IV, B], as well as in patients undergoing R1 or R2 resection [IV, B] (Fig. 1).

Regarding postoperative RT in TET, it is recommended to use: (1) 3D conformal radiotherapy or intensity-modulated radiotherapy, which has become more widely available and better preserves normal lung and heart (III, A). (2) A total dose of 45-50 Gy after complete resection, 56 Gy after R1 resection, with a boost to areas of likely residual disease, marked with clips [IV, B]. The treatment volume may include the involved nodes [IV, B] and the site of a resected pleural implant [IV, C]. (3) Conventional fractionation scheme

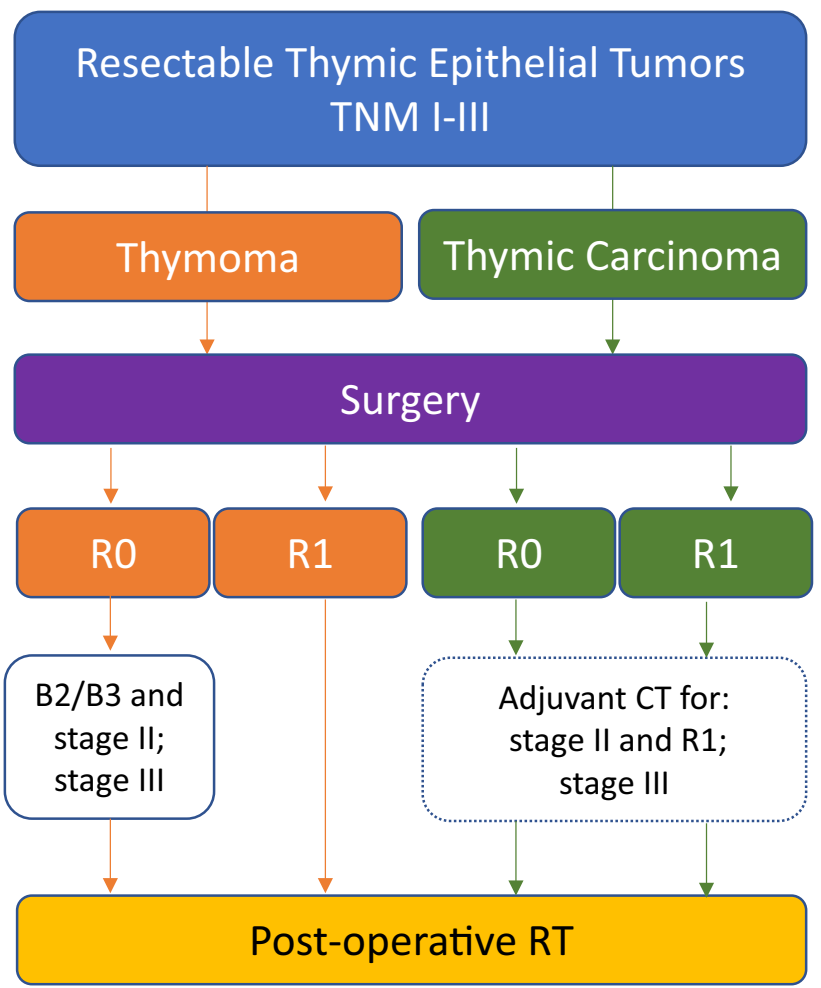

Not completely accepted. RT: Radiotherapy

Fig. 1 Management of patients with thymic epithelial tumours and resectable disease

consisting of daily doses of 1.8-2 Gy over 4-6 week period. Postoperative radiotherapy should start within 3 months of the surgical procedure [IV, B].

At diagnosis, nearly $30 \%$ of patients with TET have unresectable locally advanced disease. In these cases, RT can be delivered concurrently with chemotherapy (platinum and etoposide) either as definitive treatment dose of RT 60 to $66 \mathrm{~Gy},[\mathrm{~V}, \mathrm{C}]\}$ or as a neoadjuvant approach followed by surgery $[\mathrm{V}, \mathrm{C}]$. In patients receiving induction chemotherapy, definitive sequential RT can be applied if the patient is not deemed a surgical candidate [III, A] [30] (Fig. 2). For those patients with induction chemotherapy followed by surgery, postoperative RT should be applied in case of TC, R1 or R2 resection [IV, B] and T with stage III [IV, B] or IIB if B2/B3 subtype [IV, C].

Finally, in unresectable local recurrences, exclusive radiotherapy may be useful (Fig. 3). 


\section{Locally advanced Thymic Epithelial Tumors TNM III-IVA}

\section{Platinum-based chemotherapy*}

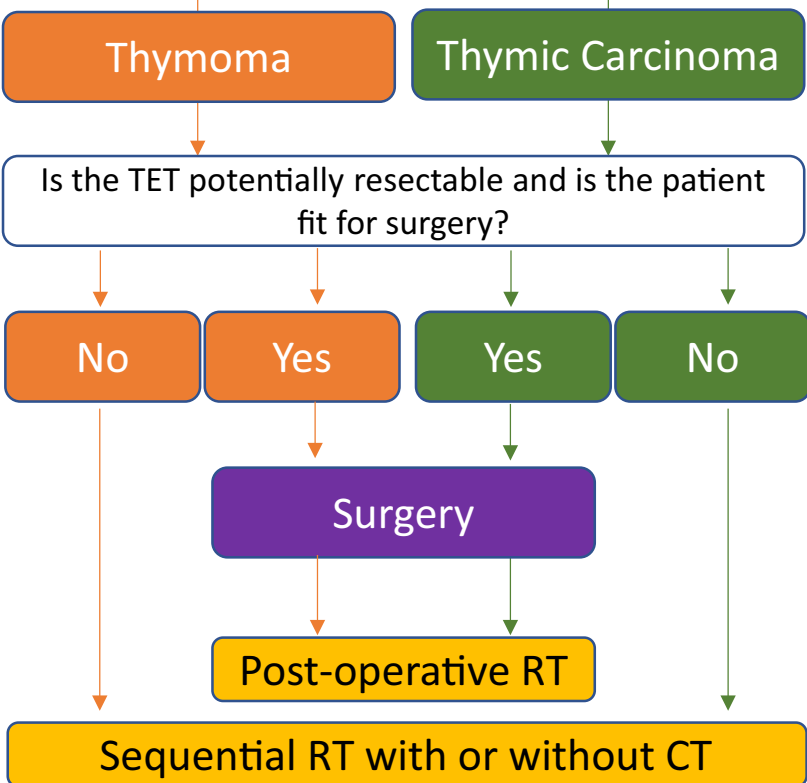

Fig. 2 Management of patients with thymic epithelial tumours and locally advanced disease

\section{Chemotherapy}

\section{Perioperative setting}

There is currently no indication for adjuvant chemotherapy in patients with R0 or R1 resection of thymoma [III, E]. Although still controversial, in TC adjuvant chemotherapy should be considered as an option for stage II with positive margins and stage III, in particular if chemotherapy has not used as induction treatment [V, C] [31] (Fig. 1).

Two to four cycles of induction chemotherapy is indicated in patients with stage III/IVA TET according to TNM classification [III, A] not suitable for upfront surgery (Fig. 2). Induction chemotherapy has shown a response rate (RR) of $\sim 70 \%$, and at least half of these patients may achieve a complete resection $[19,32]$. Surgery should be offered to patients whom complete resection is deemed achievable after induction chemotherapy [III, A]. However, if R0 resection is not achievable or if the patient is not in good enough general condition for surgery, sequential definitive RT is recommended [III, A]. There is no standard chemotherapy [33], but the RR of cisplatin, doxorubicin and cyclophosphamide (PAC) is similar in T and in TC, and is associated with
Unresectable Thymic Epithelial Tumor

not suitable for local strategies, TNM IV

\section{Biopsy}

\section{Thymoma}

Thymic Carcinoma

Platinum-based chemotherapy

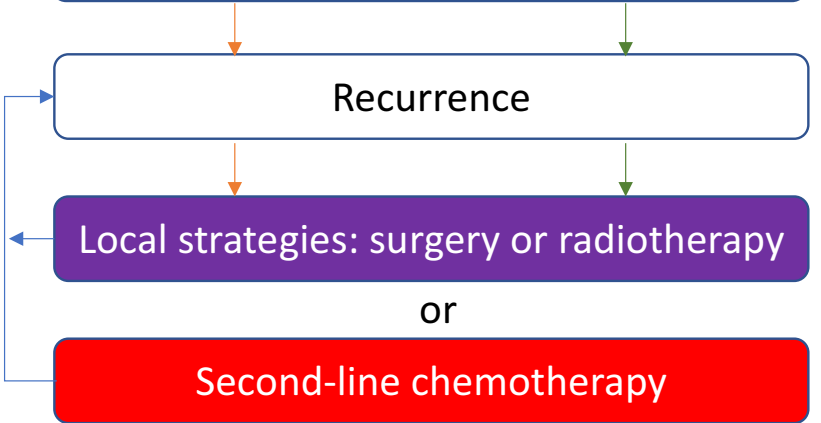

Fig. 3 Management of patients with thymic epithelial tumours and advanced disease not suitable for local strategies

longer time to progression [19]. Other potential induction chemotherapy schedules include carboplatin and paclitaxel and cisplatin and etoposide [19,33]. Although concurrent induction chemoradiotherapy may provide higher complete resection rates compared with induction chemotherapy alone, it is associated with a higher incidence of toxicity and postoperative complications [V, C] [32].

\section{Management of advanced disease}

\section{First-line setting}

In patients with metastatic disease with no intent of subsequent local treatment, definitive systemic chemotherapy is the standard of care [III, A]. Up to six cycles of cisplatin-based multi-agent combinations are recommended in this setting [21,33], such as PAC (again, the most frequently used), carboplatin plus paclitaxel, and cisplatin plus etoposide, the former particularly in TC [19] (Table 5). Gemcitabine-platinum and paclitaxel platinum shows similar outcomes in TC [34]. In the metastatic setting, the RR with PAC was similar regardless of histologic subtype, but the RR with PAC were higher versus other regimens [19]. These strategies taken together provided a RR of $\sim 30 \%$ and a median PFS of $\sim 6$ months 
Table 5 Selected treatment regimens for advanced thymic epithelial tumours assessed in phase II trials

\begin{tabular}{lll}
\hline Regimen & Agents & Doses \\
\hline PAC & Cisplatin & $50 \mathrm{mg} / \mathrm{m}^{2} \mathrm{IV} / \mathrm{Q} 3 \mathrm{~W}$ \\
& Doxorubicin & $50 \mathrm{mg} / \mathrm{m}^{2} \mathrm{IV} / \mathrm{Q} 3 \mathrm{~W}$ \\
Carboplatin/paclitaxel & Cyclophosphamide & $500 \mathrm{mg} / \mathrm{m}^{2} \mathrm{IV} / \mathrm{Q} 3 \mathrm{~W}$ \\
& Carboplatin & AUC 5-6 IV/Q3W \\
Cisplatin/etoposide & Paclitaxel & $175-200 \mathrm{mg} / \mathrm{m}^{2}$ IV/Q3W \\
& Cisplatin & $60-75 \mathrm{mg} / \mathrm{m}^{2}$ d1/Q3W \\
VIP & Etoposide & $100 \mathrm{mg} / \mathrm{m}^{2} \times 3$ days IV/Q3W \\
& Etoposide & $75 \mathrm{mg} / \mathrm{m}^{2} \times 4$ days IV/Q3W \\
Pemetrexed & Ifosfamide & $1.2 \mathrm{~g} / \mathrm{m}^{2} \times 4$ days IV/Q3W \\
Capecitabine/gemcitabine & Cisplatin & $20 \mathrm{mg} / \mathrm{m}^{2} \times 4$ days/Q3W \\
& Pemetrexed & $500 \mathrm{mg} / \mathrm{m}^{2}$ IV/Q3W \\
Oral etoposide & Capecitabine & $650 \mathrm{mg} / \mathrm{m}^{2}$ bid $\times 14$ days/Q3W \\
Everolimus & Gemcitabine & $1000 \mathrm{mg} / \mathrm{m}^{2}$ day 1 and 8 IV/Q3W \\
Sunitinib & Etoposide & $25 \mathrm{mg} / 8 \mathrm{~h}$ day $1-21 / \mathrm{QW}$ \\
Lenvatinib & Everolimus & $5-10 \mathrm{mg} /$ day, continuous \\
\hline
\end{tabular}

$I V$ intravenous, $Q 3 W$ every 3 weeks, $Q 4 W$ every 4 weeks, $Q 6 W$ every 6 weeks
[19] with prolonged median OS (more than 3 years) [33], suggesting that patients with TET may receive several subsequent treatment lines.

Recurrences in TET are not rare and should be managed as newly diagnosed tumours. In case of potentially resectable recurrent disease, surgery or other local strategies should be assessed instead of systemic treatment [35]. If not deemed possible, re-administration of a previously effective treatment must be discussed [IV, B], especially in case of previous response and late recurrence $[36,37]$. Potential cardiac toxicity with anthracyclines and previous mediastinal radiotherapy should be taken into account in case of re-treatment with PAC (Fig. 3).

\section{Second-line and beyond}

Owing to the rarity of this tumour, there is limited information about standard second-line chemotherapy, but subsequent treatment lines are indicated [III, B]. Although there is no significant difference in outcome between monotherapy and multidrug chemotherapy in TC [37], carboplatin and paclitaxel [III, B] is an accepted regimen in this setting regardless of the histologic subtype [19]. Other potential chemotherapeutic second-line schedules include pemetrexed [III, B], particularly in thymoma [38], oral etoposide [IV, B] [39] and gemcitabine and capecitabine [III, B] [40] (Table 5). The RR decreases with subsequent chemotherapy lines [19].

\section{Targeted therapies and immunotherapy}

Although TET may have somatic mutations, a personalized treatment approach is challenging because these tumours are enriched by HRAS, NRAS, TP53 and GTF2I mutations, with a limited number of actionable mutations suitable for a targeted therapy [41]. Several pathways involved in TET being explored as potential therapies in previously treated patients, such as tyrosine kinase inhibitors (TKI) and immune checkpoint inhibitors (ICI). However, none of these potential treatment strategies have received approval by the European Medcines Agency.

Tc-KIT mutation occurs in $10 \%$ of TC, however, the efficacy of c-KIT inhibitors is limited [5]. However, other multi-TKIs with antiangiogenic properties have reported clinical activity mainly in TC such as sunitinib at $50 \mathrm{mg}, 4$ weeks on 2 weeks off (RR: 26\%, median PFS: 7.2 months) [III,A][5] and lenvatinib at $24 \mathrm{mg} /$ day (RR: $39 \%$, PFS 9.6 months) [42]. However, due to evidence of grade 3 cardiovascular toxicity leading to lenvatinib discontinuation in $17 \%$ of patients, it is recommended to initiate treatment with lenvatinib at $14 \mathrm{mg} /$ day and prospectively increase the dose according to the tolerance [III, A]. Everolimus (10 mg/day), an mTOR TKI, has shown activity in TET with a disease control rate of $88 \%$ and median PFS of 10.1 months (16.6 months in $\mathrm{T}$ and 5.6 months in TC) [III, A] [5]. Careful toxicity monitoring is advised due to the potential risk of pulmonary toxicity with everolimus. 
TET has the lowest mutational burden among adult cancers [41]; and only $6 \%$ metastatic TC have a burden $>10$ mutations/megabase (mut/Mb), and 3\% have $>20 \mathrm{mut} / \mathrm{Mb}$ [43]. In contrast, PD-L1 expression in TET ranges from 34 to $94 \%$ using different cut-off points [5]; however, the prognosis and predictive value of PD-L1 expression is unclear. This evidence prompted researchers to evaluate the role of ICI in TET, mainly in TC, as AIDs are uncommon in patients with TC. In two phase II studies, pembrolizumab showed a RR of $\sim 20 \%$ and median PFS of $\sim 5$ months, and high PD-L1 expression correlated with better outcomes. However, immune-related adverse events (ir-AE) occurred in up to $20 \%$ of patients [5]. Although in a Japanese trial nivolumab did not show RR in TC [5], a recent phase II NIVOTHYM trial testing nivolumab (240 mg every 2 weeks) in B3 thymoma and TC $(N=55)$ reported a RR of $12 \%$, with $52 \%$ of patients without progression at 6 months and a median OS of 21.3 months. The second cohort of the trial testing the combination of nivolumab plus ipilimumab is ongoing [44]. Finally, in a phase I trial, avelumab showed efficacy in 7 cases of T (RR of 29\%), but was accompanied by an unacceptable high frequency of ir-AEs [5]. The efficacy of the combination of ICI and anti-angiogenics is being tested in several clinical trials (NCT04710628, NCT03463460). All these data suggest that ICI may play a role in TET, although it is not currently the standard of care. Indeed, there is strong evidence that patients with T or AIDs should not receive ICI, and off-label administration of ICI should only be performed under strict monitoring.

\section{Surveillance}

While a relapse might still be suitable for radical treatment, patients benefit from regular radiological assessment. Potential recommendations are $[\mathrm{V}, \mathrm{C}][21]$ :

(1) Baseline CT scan within 3-4 months after surgical resection.

(2) For completely resected stage I-II thymoma: annual CT scan for 5 years, then every 2 years.

(3) For stage III-IV thymoma, thymic carcinoma or after R1 or R2 resection: CT scan every 6 months for 3-5 years, thereafter annually.

(4) Continue follow-up for 10-15 years.

A flare-up of AIDs may suggest tumour recurrence, and early radiological assessment to rule out recurrence is recommended.

Patients with TETs should be encouraged to get vaccinated against COVID-19 with mRNA vaccines. Tolerability in patients with TETs is comparable to the general population, and $15 \%$ of patients developed mild flare-up of AID after some of two injections [45].

Acknowledgements To Dr Cécile Le Pechoux from Department of Radiation Oncology, Gustave Roussy, Villejuif, France, for her review in the radiotherapy section of this manuscript.

\section{Declarations}

Conflict of interest JR reports advisory board membership from MSD, BMS, BOHERING INGLEHEIM, ASTRAZENECA and OSE-IMMUOTHERAPEUTICS. RBC has nothing to disclose. PDT reports advisory board membership and speaker's fees from BMS, AstraZeneca, Boehringer Ingelheim, ROCHE, MSD and TAKEDA; grant from AstraZeneca and speaker's fees from Pfizer and Amgen. EF reports consultant fees or advisory position from AMGEN, AstraZeneca, Bayer, Boehringer Ingelheim, Bristol-Myers Squibb, Eli Lilly, GSK, Janssen, Merck Serono, MSD Oncology, Novartis, Pfizer, Roche, Sanofi, Takeda, and Peptomyc. Speaker's fees from AstraZeneca, Bristol-Myers Squibb, Eli Lilly, Medscape, Merck Sharp \& Dohme, Peer Voice, Pfizer, Roche, Takeda and CME Outfitters. Research funding from Fundación Merck Salud and Merck KGaA. Other Relationship from GRIFOLS. JLGL has nothing to disclose. MLQ reports advisory board membership and speaker's fees from BMS, MSD, Boehringer Ingelheim, AstraZeneca and Roche. XMR has nothing to disclose. ASH reports and speaker's fees from BMS and Roche; Advisory board membership from Sanofi, Astra Zeneca, Novartis, Janssen, Takeda and Pfizer. IS reports advisory board membership, speaker's fees and grants from Roche, Novartis Boehringer Ingelheim; speaker's fees and grants from Bristol-Myers Squibb, Pfizer and Merck Sharp \& Dohme; speaker's fees and grants from AstraZeneca. BM has nothing to disclose.

Ethical approval This article does not contain any studies with human or animal subjects performed by the any of the authors..

Informed consent For this type of study informed consent is not required.

Open Access This article is licensed under a Creative Commons Attribution 4.0 International License, which permits use, sharing, adaptation, distribution and reproduction in any medium or format, as long as you give appropriate credit to the original author(s) and the source, provide a link to the Creative Commons licence, and indicate if changes were made. The images or other third party material in this article are included in the article's Creative Commons licence, unless indicated otherwise in a credit line to the material. If material is not included in the article's Creative Commons licence and your intended use is not permitted by statutory regulation or exceeds the permitted use, you will need to obtain permission directly from the copyright holder. To view a copy of this licence, visit http://creativecommons.org/licenses/by/4.0/.

\section{References}

1. Dykewicz CA, Centers for Disease Control and Prevention (U.S.), Infectious Diseases Society of America, American Society of Blood and Marrow Transplantation. Summary of the guidelines for preventing opportunistic infections among hematopoietic stem cell transplant recipients. Clin Infect Dis. 2001;33:139-44. https:// doi.org/10.1086/321805. 
2. Marx A, Chan JKC, Coindre J-M, Detterbeck F, Girard N, Harris NL, et al. The 2015 World Health Organization classification of tumors of the thymus: continuity and changes. J Thorac Oncol. 2015;10:1383-95. https://doi.org/10.1097/JTO.0000000000 000654.

3. Gatta G, Capocaccia R, Botta L, Mallone S, De Angelis R, Ardanaz E, et al. Burden and centralised treatment in Europe of rare tumours: results of RARECAREnet-a population-based study. Lancet Oncol. 2017;18:1022-39. https://doi.org/10.1016/S14702045(17)30445-X

4. http://www.madrid.org/bvirtual/BVCM050184.pdf. Acessed 02 Feb 2022

5. Conforti F, Pala L, Giaccone G, De Pas T. Thymic epithelial tumors: from biology to treatment. Cancer Treat Rev. 2020;86: 102014. https://doi.org/10.1016/j.ctrv.2020.102014.

6. De Toma G, Plocco M, Nicolanti V, Brozzetti S, Letizia C, Cavallaro A. Type B1 thymoma in multiple endocrine neoplasia type 1 (MEN-1) syndrome. Tumori. 2001;87:266-8.

7. Badve SS, Dougherty R, Balatico M, Kesler KA, Loehrer P, Gökmen-Polar Y. Thymic carcinomas and second malignancies: a single-center review. Cancers (Basel). 2021;13:2472. https://doi. org/10.3390/cancers 13102472

8. Mariano C, Ionescu DN, Cheung WY, Ali RH, Laskin J, Evans K, et al. Thymoma: a population-based study of the management and outcomes for the province of British Columbia. J Thorac Oncol. 2013;8:109-17. https://doi.org/10.1097/JTO.0b013e318276241c.

9. Seki S, Koyama H, Ohno Y, Nishio M, Takenaka D, Maniwa $\mathrm{Y}$, et al. Diffusion-weighted MR imaging vs multi-detector row CT: direct comparison of capability for assessment of management needs for anterior mediastinal solitary tumors. Eur J Radiol. 2014;83:835-42. https://doi.org/10.1016/j.ejrad.2014.01.005.

10. Gentili F, Pelini V, Lucii G, Luzzi L, Mazzei FG, Fausto A, et al. Update in diagnostic imaging of the thymus and anterior mediastinal masses. Gland Surg. 2019;8:S188-207. https://doi.org/10. 21037/gs.2019.05.06.

11. Suster D, Suster S. The role of needle core biopsies in the evaluation of thymic epithelial neoplasms. J Am Soc Cytopathol. 2020;9:346-58. https://doi.org/10.1016/j.jasc.2020.04.006.

12. Montanez JCB, Boucher M-É, Dansin E, Kerjouan M, Mazieres J, Pichon E, et al. Autoimmune diseases in centrally reviewed thymic epithelial tumours (TET). Ann Oncol. 2020;31:S1078. https://doi.org/10.1016/j.annonc.2020.08.1442.

13. Padda SK, Yao X, Antonicelli A, Riess JW, Shang Y, Shrager $\mathrm{JB}$, et al. Paraneoplastic syndromes and thymic malignancies: an examination of the international thymic malignancy interest group retrospective database. J Thorac Oncol. 2018;13:436-46. https:// doi.org/10.1016/j.jtho.2017.11.118.

14. Anderson MS, Su MA. Aire and T cell development. Curr Opin Immunol. 2011;23:198-206. https://doi.org/10.1016/j.coi.2010. 11.007 .

15. Detterbeck FC, Nicholson AG, Kondo K, Van Schil P, Moran C. The Masaoka-Koga stage classification for thymic malignancies: clarification and definition of terms. J Thorac Oncol. 2011;6:S1710-1716. https://doi.org/10.1097/JTO.0b013e3182 $1 \mathrm{e} 8 \mathrm{cff}$.

16. Detterbeck FC, Stratton K, Giroux D, Asamura H, Crowley J, Falkson C, et al. The IASLC/ITMIG thymic epithelial tumors staging project: proposal for an evidence-based stage classification system for the forthcoming (8th) edition of the TNM classification of malignant tumors. J Thorac Oncol. 2014;9:S65-72. https://doi. org/10.1097/JTO.0000000000000290.

17. Meurgey A, Girard N, du Vignaux CM, Maury J-M, Tronc F, Thivolet-Bejui F, et al. Assessment of the ITMIG statement on the WHO histological classification and of the eighth TNM staging of thymic epithelial tumors of a series of 188 thymic epithelial tumors. J Thorac Oncol. 2017;12:1571-81. https://doi.org/10. 1016/j.jtho.2017.06.072.

18. Rosell L, Wihl J, Hagberg O, Ohlsson B, Nilbert M. Function, information, and contributions: an evaluation of national multidisciplinary team meetings for rare cancers. Rare Tumors. 2019;11:2036361319841696. https://doi.org/10.1177/2036361319 841696.

19. du Vignaux CM, Dansin E, Mhanna L, Greillier L, Pichon E, Kerjouan M, et al. Systemic therapy in advanced thymic epithelial tumors: insights from the RYTHMIC prospective cohort. J Thorac Oncol. 2018;13:1762-70. https://doi.org/10.1016/j.jtho. 2018.08.005.

20. Basse C, Thureau S, Bota S, Dansin E, Thomas P-A, Pichon E, et al. Multidisciplinary tumor board decision making for postoperative radiotherapy in thymic epithelial tumors: insights from the RYTHMIC prospective cohort. J Thorac Oncol. 2017;12:171522. https://doi.org/10.1016/j.jtho.2017.07.023.

21. Girard N, Ruffini E, Marx A, Faivre-Finn C, Peters S, ESMO Guidelines Committee. Thymic epithelial tumours: ESMO clinical practice guidelines for diagnosis, treatment and follow-up. Ann Oncol. 2015;26:v40-55. https://doi.org/10.1093/annonc/mdv277 (Suppl 5).

22. Detterbeck FC. Evaluation and treatment of stage I and II thymoma. J Thorac Oncol. 2010;5:S318-322. https://doi.org/10.1097/ JTO.0b013e3181f20dab.

23. Davenport E, Malthaner RA. The role of surgery in the management of thymoma: a systematic review. Ann Thorac Surg. 2008;86:673-84. https://doi.org/10.1016/j.athoracsur.2008.03. 055 .

24. Wright CD. Pleuropneumonectomy for the treatment of Masaoka stage IVA thymoma. Ann Thorac Surg. 2006;82:1234-9. https:// doi.org/10.1016/j.athoracsur.2006.05.028.

25. Benítez JC, Bluthgen MV, Boucher M, Dansin E, Kerjouan M, Bigay-Game L, et al. Multimodality treatment and outcome in stage III thymic epithelial tumors (TETs): a retrospective analysis from the French RYTHMIC network. J Thorac Oncol. 2021;16:S895-6. https://doi.org/10.1016/j.jtho.2021.08.123.

26. Hamdi S, Mercier O, Fadel E, Mussot S, Fabre D, Ghigna MR, et al. Is sacrifying the phrenic nerve during thymoma resection worthwhile? Eur J Cardiothorac Surg. 2014;45:e151-155. https:// doi.org/10.1093/ejcts/ezu025.

27. Friedant AJ, Handorf EA, Su S, Scott WJ. Minimally invasive versus open thymectomy for thymic malignancies: systematic review and meta-analysis. J Thorac Oncol. 2016;11:30-8. https://doi.org/ 10.1016/j.jtho.2015.08.004.

28. Ruffini E, Detterbeck F, Van Raemdonck D, Rocco G, Thomas P, Weder W, et al. Thymic carcinoma: a cohort study of patients from the European society of thoracic surgeons database. J Thorac Oncol. 2014;9:541-8. https://doi.org/10.1097/JTO.0000000000 000128.

29. Jackson MW, Palma DA, Camidge DR, Jones BL, Robin TP, Sher DJ, et al. The impact of postoperative radiotherapy for thymoma and thymic carcinoma. J Thorac Oncol. 2017;12:734-44. https:// doi.org/10.1016/j.jtho.2017.01.002.

30. Loehrer PJ, Chen M, Kim K, Aisner SC, Einhorn LH, Livingston $\mathrm{R}$, et al. Cisplatin, doxorubicin, and cyclophosphamide plus thoracic radiation therapy for limited-stage unresectable thymoma: an intergroup trial. J Clin Oncol. 1997;15:3093-9. https://doi.org/ 10.1200/JCO.1997.15.9.3093.

31. Kim S, Bull DA, Hsu C-H, Hsu CC. The role of adjuvant therapy in advanced thymic carcinoma: A National Cancer Database Analysis. Ann Thorac Surg. 2020;109:1095-103. https://doi.org/ 10.1016/j.athoracsur.2019.11.009. 
32. Girard N. Thymic epithelial tumours: from basic principles to individualised treatment strategies. Eur Respir Rev. 2013;22:7587. https://doi.org/10.1183/09059180.00007312.

33. Berghmans T, Durieux V, Holbrechts S, Jungels C, Lafitte J-J, Meert A-P, et al. Systemic treatments for thymoma and thymic carcinoma: a systematic review. Lung Cancer. 2018;126:25-31. https://doi.org/10.1016/j.lungcan.2018.10.018.

34. Yang X, Zhuo M, Shi A, Yang S, Wang Z, Wu M, et al. Optimal first-line treatment for advanced thymic carcinoma. Thorac Cancer. 2019;10:2081-7. https://doi.org/10.1111/1759-7714.13181.

35. Sandri A, Cusumano G, Lococo F, Alifano M, Granone P, Margaritora S, et al. Long-term results after treatment for recurrent thymoma: a multicenter analysis. J Thorac Oncol. 2014;9:1796-804. https://doi.org/10.1097/JTO.0000000000000370.

36. Lara PN, Bonomi PD, Faber LP. Retreatment of recurrent invasive thymoma with platinum, doxorubicin, and cyclophosphamide. Chest. 1996;110:1115-7. https://doi.org/10.1378/chest.110.4. 1115.

37. Tateishi K, Ko R, Shukuya T, Okuma Y, Watanabe S, Kuyama S, et al. Clinical outcomes of second-line chemotherapy in patients with previously treated advanced thymic carcinoma: a retrospective analysis of 191 patients from the NEJ023 study. Oncologist. 2020;25:e668-74. https://doi.org/10.1634/theoncologist. 2019-0593.

38. Gbolahan OB, Porter RF, Salter JT, Yiannoutsos C, Burns M, Chiorean EG, et al. A phase II study of pemetrexed in patients with recurrent thymoma and thymic carcinoma. J Thorac Oncol. 2018;13:1940-8. https://doi.org/10.1016/j.jtho.2018.07.094.

39. Bluthgen MV, Boutros C, Fayard F, Remon J, Planchard D, Besse B. Activity and safety of oral etoposide in pretreated patients with metastatic or recurrent thymic epithelial tumors (TET): a singleinstitution experience. Lung Cancer. 2016;99:111-6. https://doi. org/10.1016/j.lungcan.2016.06.020.
40. Palmieri G, Buonerba C, Ottaviano M, Federico P, Calabrese F, Von Arx C, et al. Capecitabine plus gemcitabine in thymic epithelial tumors: final analysis of a phase II trial. Future Oncol. 2014;10:2141-7. https://doi.org/10.2217/fon.14.144.

41. Radovich M, Pickering CR, Felau I, Ha G, Zhang H, Jo H, et al. The integrated genomic landscape of thymic epithelial tumors. Cancer Cell. 2018;33:244-258.e10. https://doi.org/10.1016/j.ccell. 2018.01.003.

42. Sato J, Satouchi M, Itoh S, Okuma Y, Niho S, Mizugaki H, et al. Lenvatinib in patients with advanced or metastatic thymic carcinoma (REMORA): a multicentre, phase 2 trial. Lancet Oncol. 2020;21:843-50. https://doi.org/10.1016/S1470-2045(20) 30162-5.

43. Ross JS, Vanden Borre P, Almog N, Schrock AB, Chung J, Vergilio J-A, et al. Comprehensive genomic profiling (CGP) of thymic gland carcinomas. Ann Oncol. 2017;28:v595-6. https:// doi.org/10.1093/annonc/mdx391.001.

44. Girard N, Ponce Aix S, Cedres S, Berghmans T, Burgers S, Toffart AC, et al. Efficacy and safety of nivolumab for patients with pre-treated type B3 thymoma and thymic carcinoma: results from the EORTC-ETOP NIVOTHYM phase II trial. Ann Oncol. 2021;32:S1342. https://doi.org/10.1016/j.annonc.2021.08.2147.

45. Ballman M, Swift S, Mullenix C, Mallory Y, Zhao C, Szabo E, et al. Tolerability of coronavirus disease 2019 vaccines, BNT162b2 and mRNA-1273, in patients with thymic epithelial tumors. JTO Clin Res Rep. 2021;2: 100229. https://doi.org/10. 1016/j.jtocrr.2021.100229.

Publisher's Note Springer Nature remains neutral with regard to jurisdictional claims in published maps and institutional affiliations. 